\title{
Ocorrência de leveduras na cavidade oral e traqueia de aves de rapina
}

\author{
[Occurrence of yeasts in the oral cavity and trachea of birds of prey]
}

\section{"Artigo Científico/Scientific Article"}

\author{
Davi Rubem da Silva ${ }^{1 *}$, José Sérgio Alcântara e Silva ${ }^{2}$, Samuel David Silva Ferreira ${ }^{2}$, \\ Roberto Citelli de Farias $^{3}$, Reginaldo Gonçalves de Lima-Neto ${ }^{4}$, Cristina Maria de Souza-Motta ${ }^{5}$, \\ Rinaldo Aparecido Mota ${ }^{6}$, Andrea Alice da Fonseca Oliveira ${ }^{6}$, Atzel Candido Acosta Abad ${ }^{6}$, \\ José Wilton Pinheiro Junior ${ }^{6}$, Leonildo Bento Galiza da Silva ${ }^{6}$
}

\footnotetext{
${ }^{1}$ Ministério da Agricultura, Pecuária e Abastecimento, Jaguapitã-PR, Brasil

${ }^{2}$ Médico Veterinário autônomo, Brasil.

${ }^{3}$ Parque Zoobotânico Arruda Câmara, João Pessoa-PB, Brasil.

${ }^{4}$ Departamento de Medicina Tropical, Universidade Federal de Pernambuco, Recife,-PE, Brasil.

${ }^{5}$ Laboratório de Taxonomia de Fungos, Departamento de Micologia, Universidade Federal de Pernambuco, Recife-PE, Brasil.

${ }^{6}$ Departamento de Medicina Veterinária, Universidade Federal Rural de Pernambuco, Recife-PE, Brasil.

*Autor para correspondência/Corresponding author: E-mail: davirubem@yahoo.com.br
}

\begin{abstract}
Resumo
Objetivou-se com esta pesquisa isolar e identificar leveduras da cavidade oral e traqueia de aves de rapina. Para este estudo, utilizaram-se 17 aves de rapina (três carcarás (Caracara plancus), 11 gaviões-carijós (Rupornis magnirostris), 1 coruja-das-torres (Tyto furcata) e duas corujas-orelhuda (Rhinoptynx clamator). As amostras foram colhidas da cavidade oral e traqueia com auxílio de swabs estéreis. Foram cultivadas 34 amostras em ágar Sabouraud dextrose com cloranfenicol $(100 \mathrm{mg} / \mathrm{L})$ e incubadas em aerobiose à temperatura ambiente por um período mínimo de sete dias e máximo de 15 dias, sendo observadas diariamente. Foram isolados $14(93,3 \%)$ amostras de leveduras da cavidade oral e apenas uma $(6,7 \%)$ da traqueia. Dos 15 isolados, 14 (93,3\%) foram obtidos de amostras de gavião-carijós (Rupornis magnirostris) e uma (6,67\%) em carcará (Caracara plancus). As espécies identificadas foram: Candida albicans (13,3\%), C. parapsilosis (20\%), C. tropicallis (26,7\%), C. magnoliae (6,78\%), Candida sp. (13,3\%) e Trichosporon cutaneum (20\%). O isolamento e identificação de leveduras em aves de rapina é epidemiologicamente importante para uma melhor compreensão dos processos patológicos na cavidade oral e na traqueia das espécies estudadas, uma vez que seu conhecimento permite adoção de medidas para a prevenção de doenças causadas por esses agentes oportunistas.
\end{abstract}

Palavras-chave: aves silvestres; micologia; diagnóstico; manejo.

\begin{abstract}
The present study aimed to isolate and identify yeast from the oral cavity and tracheae of birds of prey. For this study, 17 birds of prey (three caracaras (Caracara plancus), 11 hawks (Rupornis magnirostris), 1 tower owl (Tyto furcata) and two eared owls (Rhinoptynx clamator) were used. Samples were collected from the oral cavity and tracheae using sterile swabs. Thirty-four samples were cultured onto Sabouraud dextrose agar with chloramphenicol $(100 \mathrm{mg} / \mathrm{L})$ and incubated in aerobiosis at room temperature for a minimum of seven days and maximum of 15 days and observed daily. Fourteen (93.3\%) colonies of yeast were isolated from the oral cavity and only one $(6.7 \%)$ from the tracheae. From 15 isolates, 14 (93.3\%) were obtained from hawk (Rupornis magnirostris) specimens and one isolate (6.67\%) was obtained from caracaras (Caracara plancus). The identified species were: Candida albicans (13.3\%), C. parapsilosis (20\%), C. tropicallis (26.7\%), C. magnoliae (6.78\%), Candida sp. (13.3\%) and Trichosporon cutaneum (20\%). The isolation and identification of yeasts in birds of prey are epidemiologically important for a better understanding of pathological processes
\end{abstract}


in the oral cavity and trachea of the studied species, since that knowledge allows the adoption of measures for the prevention of diseases caused by these opportunistic agents.

Keywords: wild birds; mycology; diagnosis; handling.

\section{Introdução}

O termo aves de rapina é usualmente aplicado por ornitologistas para distinguir os falcões, gaviões, águias, urubus e corujas dos demais grupos de aves predatórias (Ferguson-Lees e Christie, 2001). Pelos hábitos alimentícios destes predadores e sua ubiquação na cadeia alimentícia já foram recomendados como alvos de estudos para monitorar os micro-organismos circulantes no ambiente, tanto bactérias (Marrow et al., 2009), vírus (Shearn-Bochsler et al., 2019) e fungos (Brilhante et al., 2012).

As leveduras são consideradas parte da microbiota normal de trato gastrointestinal, pele e sistema urinário em animais e humanos (Cafarchia et al., 2008), podendo ser a causa de infecçoes cutâneas ou sistêmicas (Deem, 2003). As infecções fúngicas, por muito tempo, têm sido um problema de saúde para as aves, não somente pela infeção direta dos tecidos moles, como também pela produção e liberação de microtoxinas nos alimentos (Richard et al., 1994). Entre as leveduras isoladas com maior frequência do trato gastrointestinal das aves destacam-se Rhodotorula rubra, Cryptococcus albidus, Candida albicans, Trichosporon cutaneum, Candida guilliermondii e Candida tropicalis (Cafarchia et al., 2006a); Rhodotorula rubra e Cryptococcus neoformans (Cafarchia et al., 2006b) e Candida albicans e Candida famata (Brilhante et al., 2012).

Em estudos realizados para pesquisas de leveduras na microbiota da parte superior do trato digestório observa-se que o gênero Candida sp. foi o mais frequente. Kocan e Hasenclever (1972) ao estudarem sete espécies de columbídeos verificaram que Candida albicans, Geotrichum sp., C. tropicalis, C. guilliermodii, Torulopsis glabrata e Sacharomyces telluris foram os principais microrganismos encontrados. $\mathrm{Na}$ pesquisa de Garcia et al. (2007) que estudaram a microbiota fúngica da traqueia de 216 aves silvestres, pertencentes a 26 espécies e sete ordens, em um centro de reabilitação na Espanha, relataram a predominância de leveduras em relação aos fungos filamentosos, cujo gênero Candida foi isolado em $65,21 \%$, sendo C. albicans $(51,67 \%)$ a espécie mais isolada.
A partir do estudo de registros clínicos de um hospital especializado no atendimento a falcões na cidade de Riyadh, no Reino da Arábia Saudita, Naldo e Samour (2004) observaram que as principais causas de morte destes animais eram doenças bacterianas e fúngicas. A candidíase é a segunda mais importante doença em aves de rapina causada por fungos depois de aspergilose (Deem, 2003).

Tendo em vista a importância do conhecimento da microbiota na compreensão das leveduras como potenciais causadores de doenças, objetivou-se com a presente pesquisa isolar e identificar leveduras da cavidade oral e traqueia de aves de rapina procedentes do centro de reabilitação localizado no município de Recife, Pernambuco.

\section{Material e Métodos}

Foram utilizadas para este estudo 17 aves de rapina (14 da ordem Falconiformes e três da ordem Strigiformes) procedente do Centro de Triagem de Animais Silvestres (CETAS), gerenciado pelo Instituto Brasileiro do Meio Ambiente e dos Recursos Naturais Renováveis (IBAMA), localizado no município de Recife, Pernambuco. O grupo de aves da ordem Falconiformes era composto por três carcarás (Caracara plancus) e 11 gaviões-carijós (Rupornis magnirostris). Na ordem Strigiformes as amostras foram colhidas de uma coruja-das-torres (Tyto furcata) e duas corujas-orelhuda (Rhinoptynx clamator).

Para a colheita das amostras os animais foram contidos fisicamente usando luvas específicas de couro; foram utilizados dois swabs estéreis, sendo um para a cavidade oral e outro para a traqueia, totalizando 34 amostras. Após a colheita, os mesmos foram encaminhados em temperatura ambiente ao laboratório para seu devido processamento. No laboratório, as amostras foram semeadas em ágar Sabouraud dextrose acrescido de cloranfenicol $(100 \mathrm{mg} / \mathrm{L})$ e incubadas em aerobiose em temperatura ambiente por um período mínimo de sete dias e máximo de 15 dias, seguindo a metodologia descrita por Melville et al. (2004). Os isolados obtidos foram encaminhados ao Laboratório de Micologia Médica do Centro de 
Ciências Biológicas/UFPE para sua identificação, onde foram avaliadas as características macroscópicas, microscópicas e provas bioquímicas. Foram realizadas as provas de produção de clamidósporo, temperatura de crescimento a $45^{\circ} \mathrm{C}$, assimilação de carboidratos e nitrogênio, urease e fermentação de carboidratos (Yarrow, 1998; Brilhante et al., 2010).

\section{Resultados}

Foi possível isolar leveduras de oito aves, o que representa $47,1 \%$ do total de aves estudadas. Das 34 amostras analisadas, 15 (44,2\%) foram positivas para presença de leveduras, sendo que 14
$(93,3 \%)$ foram isoladas da cavidade oral e apenas uma $(6,7 \%)$ da traqueia. As leveduras isoladas neste estudo encontram-se discriminadas na Tabela 1, sendo 80\% (12/15) do gênero Candida.

Considerando as espécies de aves de rapina, observou-se que 14 (93,33\%) das leveduras foram isoladas em gaviões-carijós (Rupornis magnirostris) e uma (6,67\%) em carcará (Caracara plancus) (Tabela 2). Não houve isolamento fúngico em duas espécimes, sendo um representante da espécie coruja-das-torres (Tyto furcata) e duas da espécie coruja-orelhuda (Rhinoptynx clamator).

Tabela 1. Identificação das leveduras isoladas da cavidade oral e traqueia de aves de rapina procedentes de centro de triagem.

\begin{tabular}{|c|c|c|c|c|}
\hline \multirow{2}{*}{ Leveduras } & \multicolumn{2}{|c|}{ Cavidade Oral } & \multicolumn{2}{|c|}{ Traqueia } \\
\hline & $\mathbf{F A}^{1}$ & $\mathbf{F R}^{2}$ & FA & FR \\
\hline Candida albicans & 1 & $7,1 \%$ & 1 & $100 \%$ \\
\hline Candida parapsilosis & 3 & $21,4 \%$ & - & - \\
\hline Candida tropicalis & 4 & $28,6 \%$ & - & - \\
\hline Candida magnoliae & 1 & $7,1 \%$ & - & - \\
\hline Candida sp. & 2 & $14,4 \%$ & - & - \\
\hline Trichosporon cutaneum & 3 & $21,4 \%$ & - & - \\
\hline Total & 14 & $100 \%$ & 1 & $100 \%$ \\
\hline
\end{tabular}

$\mathrm{FA}^{1}$ - Frequência Absoluta; FR ${ }^{2}$ - Frequência Relativa.

Tabela 2. Identificação das leveduras em relação às espécies de aves de rapina procedentes de centro de reabilitação localizado no município de Recife, Pernambuco.

\begin{tabular}{|c|c|c|c|c|c|c|c|}
\hline \multirow[b]{2}{*}{$\begin{array}{l}\text { Aves de } \\
\text { Rapina }\end{array}$} & \multicolumn{6}{|c|}{ Leveduras } & \multirow[b]{2}{*}{ Total } \\
\hline & $\begin{array}{c}\text { Candida } \\
\text { albicans } \\
(\%)\end{array}$ & $\begin{array}{c}\text { Candida } \\
\text { parapsilosis } \\
(\%)\end{array}$ & $\begin{array}{c}\text { Candida } \\
\text { tropicalis } \\
(\%)\end{array}$ & $\begin{array}{c}\text { Candida } \\
\text { magnoliae } \\
(\%)\end{array}$ & $\begin{array}{c}\text { Candida sp. } \\
(\%)\end{array}$ & $\begin{array}{c}\text { Trichosporon } \\
\text { cutaneum } \\
(\%)\end{array}$ & \\
\hline \multicolumn{8}{|c|}{ Carcará (Caracara plancus) } \\
\hline 1 & - & $\mathrm{CO}$ & - & - & - & - & 1 \\
\hline 2 & - & - & - & - & - & - & \\
\hline 3 & - & - & - & - & - & - & \\
\hline \multicolumn{8}{|c|}{ Gavião-carijós (Rupornis magnirostris) } \\
\hline 1 & - & - & $\mathrm{CO}$ & - & $\mathrm{CO}$ & $\mathrm{CO}$ & 3 \\
\hline 2 & - & - & $\mathrm{CO}$ & - & - & - & 1 \\
\hline 3 & - & - & $\mathrm{CO}$ & - & - & - & 1 \\
\hline 4 & - & - & - & - & - & $\mathrm{CO}$ & 1 \\
\hline 5 & - & $\mathrm{CO}$ & $\mathrm{CO}$ & - & - & - & 2 \\
\hline 6 & - & $\mathrm{CO}$ & - & $\mathrm{CO}$ & $\mathrm{CO}$ & - & 3 \\
\hline 7 & $\mathrm{CO}^{1} / \mathrm{T}^{2}$ & - & - & & & $\mathrm{CO}$ & 3 \\
\hline 8 & - & - & - & - & - & - & \\
\hline 9 & - & - & - & - & - & - & \\
\hline 10 & - & - & - & - & - & - & \\
\hline 11 & - & - & - & - & - & - & \\
\hline \multicolumn{8}{|c|}{ Coruja-das-torres (Tyto furcata) } \\
\hline 1 & - & - & - & - & - & - & \\
\hline \multicolumn{8}{|c|}{ Corujas-orelhuda (Rhinoptynx clamator) } \\
\hline 1 & - & - & - & - & - & - & \\
\hline 2 & - & - & - & - & - & - & \\
\hline Total & $2(13,3)$ & $3(20)$ & $4(26,7)$ & $1(6,7)$ & $2(13,3)$ & $3(20)$ & 15 \\
\hline
\end{tabular}




\section{Discussão}

Em um estudo prévio realizado em aves de rapina no Brasil, observou-se 72,7\% (16/22) de aves positivas a leveduras, sendo a origem das amostras swabs de esôfago inferior e cloaca (Brilhante et al., 2012). A diferença entre o resultado obtido neste estudo (frequência de $47,1 \%)$ e o resultado observado na literatura pode estar relacionada ao tipo de material biológico analisado, uma vez que neste estudo colheram-se apenas amostras da cavidade oral e traqueia. Constatando-se uma maior probabilidade de isolamento dessas leveduras no trato inferior do sistema digestório ou nas fezes dessas aves (Cafarchia et al., 2006b). Outro fator que pode justificar estas diferenças foram as formas de manejo, dentre eles o nutricional e higiênicosanitário aos quais os animais eram submetidos.

Em relação ao manejo das aves incluídas neste estudo, observou-se que o piso do recinto estava coberto com uma camada de maravalha, sendo a mesma substituída pelo menos uma vez por semana e a limpeza do piso foi realizada no mínimo duas vezes por mês. A dieta das aves era constituída de vísceras de bovino moídas descongeladas e de camundongos oferecidos vivos. As vísceras eram oferecidas em bandejas de plástico, colocadas no piso dos recintos. A água era fornecida ad libitum, em recipientes de alumínio e a troca efetuava-se diariamente. Para a higienização dos utensílios era utilizado detergente e solução de hipoclorito de sódio com uma concentração entre $10 \%$ e $13 \%$ de cloro ativo.

Uma atenção redobrada na higiene das instalações, armazenamento do alimento, umidade e temperatura do ambiente onde as aves são mantidas, constituem a base da prevenção de doenças fúngicas. Outro ponto a ser destacado é a qualidade do ar, uma vez que ambientes secos e empoeirados podem prejudicar a ação mucociliar normal do epitélio respiratório e predispor as aves a infecções respiratórias (Joseph, 2000). Neste sentido, Cafarchia et al. (2006a) indicam que a prevalência e as espécies de leveduras isoladas estão diretamente relacionadas com a ecologia, dieta e habitat das aves. A prevenção das doenças fúngicas é mais fácil do que o tratamento (Deem, 2003).

Outro resultado encontrado na presente pesquisa foi a alta porcentagem (80\%) de isolados do gênero Candida. Esta levedura produz a doença denominada candidíases, que é considerada a segunda mais importante infecção fúngica em aves de rapina (Redig, 1986). A candidíase assim como a aspergilose são mais frequentes em aves de rapina em cativeiro que nas de vida silvestre (Deem, 2003), o que justifica os cuidados redrobrados nos ambientes onde são mantidas estas aves.

Em relação aos sítios anatômicos constatouse o isolamento de $C$. albicans na cavidade oral e traqueia, de um mesmo animal. Esse achado está de acordo com os relatados por Huchzermeyer (2000), que correlacionaram a proximidade anatômica do trato respiratório à possibilidade de agentes isolados em regiões altas poderem contaminar áreas inferiores. As características anatômicas podem predispor as aves às doenças respiratórias, como a ausência da epiglote para impedir que pequenas partículas penetrem na parte mais baixa do trato respiratório, ausência do diafragma tendo por resultado a inabilidade de produzir o forte reflexo da tosse, e uma distribuição limitada do epitélio pseudo-estratificado colunar ciliado através do trato respiratório (Tell, 2005).

Neste estudo não foram observadas aves com sinais clínicos de doença fúngica. Contudo, devido ao fato de que $47,1 \%$ do total das aves estudadas serem positivas a pelo menos um isolado de levedura nos sítios anatômicos estudados, pode ser um sinal de alerta para a saúde das aves de rapinas mantidas em cativeiro, uma vez que fatores de riscos extrínsecos e intrínsecos podem favorecer o desencadeamento de enfermidades fúngicas. Entre os fatores de riscos extrínsecos podem ser mencionados: condições ambientais inadequadas, mudança na dieta, nutrição deficiente, contenção, confinamento, transporte e prolongada terapia com antibióticos ou esteroides (Deem, 2003; Garcia et al., 2007). Além disso, Cafarchia et al. (2006b) sugerem uma importante participação das aves de rapina como disseminadoras de leveduras no ambiente, incluindo leveduras zoonóticas. Esta condição, pode constituir um fator de risco para a saúde das pessoas que laboram no centro de reabilitação e ratifica a necessidade de uso contínuo de meios de proteção por parte dos trabalhadores e o saneamento ambiental dos locais onde são mantidas estas aves.

\section{Conclusão}

Considerando a alta frequência de isolamento de leveduras, especialmente em amostras obtidas de gavião-carijós (Rupornis magnirostris), sugere-se que existe contaminação ambiental e medidas de controle ambiental devem ser adotadas para evitar a ocorrência de doenças 
causadas por estes agentes oportunistas. Além disso, recomenda-se avaliar o perfil de sensibilidade in vitro a antifúngicos para contribuir com o monitoramento ambiental da resistência a estes agentes.

\section{Conflito de Interesse}

Os autores declaram não existir conflito de interesse.

\section{Referências}

Brilhante, R.S.; Castelo Branco D.S.; Duarte G.P.; Paiva M.A.; Teixeira C.E.; Zeferino J.P.; Monteiro A.J.; Cordeiro R.A.; Sidrim J.J.; Rocha, M.F. Yeast microbiota of raptors: a possible tool for environmental monitoring. Environmental Microbiology Reports, 4(2): 189-193, 2012.

Brilhante, R.S.N.; Castelo-Branco D.; Soares G.; Astete-Medrano D.J.; Monteiro A.J.; Cordeiro R.D.A.; Sidrim J.J.C.; Rocha M.F.G. Characterization of the gastrointestinal yeast microbiota of cockatiels (Nymphicus hollandicus): a potential hazard to human health. Journal of Medical Microbiology, 59(6): 718-723, 2010.

Cafarchia, C.; Camarda A.; Romito D.; Campolo M.; Quaglia N.C.; Tullio D.; Otranto D. Occurrence of yeasts in cloacae of migratory birds. Mycopathologia, 161(4): 229-234, 2006a.

Cafarchia, C.; Romito D.; Coccioli C.; Camarda A.; Otranto D. Phospholipase activity of yeasts from wild birds and possible implications for human disease. Sabouraudia, 46(5): 429-434, 2008.

Cafarchia, C.; Romito D.; Iatta R.; Camarda A.; Montagna M.; Otranto D. Role of birds of prey as carriers and spreaders of Cryptococcus neoformans and other zoonotic yeasts. Medical Mycology, 44(6): 485-492, 2006b.

Deem, S.L. Fungal diseases of birds of prey. Veterinary Clinics of North America: Exotic Animal Practice, 6(2): 363-376, 2003.

Ferguson-Lees, J.; Christie D.A. Raptors of the world. Boston: Houghton Mifflin, 2001. 992 p.

Garcia, M.; Lanzarot P.; Rodas V.; Costas E.; Blanco J. Fungal flora in the trachea of birds from a wildlife rehabilitation centre in Spain.
Veterinarni Medicina-Praha-, 52(10): 464470, 2007.

Huchzermeyer, F. Doenças de avestruzes e outras ratitas. Jaboticabal: Funep, 2000. p. 321-366,

Joseph, V., Aspergillosis in raptors. Seminars in Avian and Exotic Pet Medicine, 9(2): 66-74, 2000.

Kocan, R., Hasenclever H. Normal yeast flora of the upper digestive tract of some wild columbids. Journal of Wildlife Diseases, 8(4): 365-368, 1972.

Marrow, J.; Whittington J.K.; Mitchell M.; Hoyer L.L.; Maddox C. Prevalence and antibioticresistance characteristics of Enterococcus spp. isolated from free-living and captive raptors in Central Illinois. Journal of Wildlife Diseases, 45(2): 302-313, 2009.

Melville, P.A.; Cogliati B.; Mangiaterra M.B.B.C.D.; Peres M.R.; Moura S.C.A.; Matsuda L.; Kim A.; Benites N.R. Determinação da microbiota presente na cloaca e orofaringe de avestruzes (Struthio camelus) clinicamente sadios. Ciência Rural, 34(6): 1871-1876, 2004.

Naldo, J.L.; Samour J.H. Causes of morbidity and mortality in falcons in Saudi Arabia. Journal of Avian Medicine and Surgery, 18(4): 229-241, 2004.

Redig, P.T. Mycotic infections of birds of prey. In:__ Zoo and wild animal medicine. Philadelphia: Saunders, 1986. p.420-425.

Richard, J.L.; Debey, M.C.; Chermette, R.; Pier, A.C.; Hasegawa, A.; Lund, A.; Bratberg, A.M.; Padhye, A.A.; Connole, M.D. Advances in veterinary mycology. Journal of Medical and Veterinary Mycology, 32(sup1): 169-187, 1994.

Shearn-Bochsler, V.I.; Knowles, S.; Hon, I. Lethal infection of wild raptors with highly pathogenic avian influenza $\mathrm{H} 5 \mathrm{~N} 8$ and $\mathrm{H} 5 \mathrm{~N} 2$ viruses in the USA, 2014-15. Journal of Wildlife Diseases, 55(1): 164-168, 2019.

Tell, L. A. Aspergillosis in mammals and birds: impact on veterinary medicine. Medical Mycology, 43(Supplement 1): 71-73, 2005.

Yarrow, D. Methods for the isolation, maintenance and identification of yeasts. In: Fell, J.W. The yeasts, a taxonomic study. $4^{\text {th }} \mathrm{ed}$. Amsterdam: Elsevier, 1998. p.77-100. 